\title{
NOBEL AND HIS PRIZES
}

$I^{N}$ 1950 the Nobel Foundation celebrated its fiftieth anniversary. An account of the ceremonies marking the event has already appeared in Nature of January 13 by Prof. G. Hevesy, himself a Nobel prize winner, together with some details of the book before us*; but not much was related by him of the man Alfred Nobel. Born in 1833, son of a somewhat unsuccessful but brilliant technician, he only received one year's schooling, at the age of eight, and no university education. Unusually intelligent, he was a dreamy, introspective youth; private tuition had made of him by the age of sixteen a remarkable linguist and a scientifically trained chemist. An improvement in the manufacture of nitroglycerine was followed by the invention of dynamite, and he became at an early age the head of a world industry. He never took root in a home but spent most of his time in railway carriages, steamship cabins and hotels. A strong disinclination to allow anyone to become too close to him was offset by a strong need for an intimate friend on whose devotion he could rely in all circumstances. Inner contradictions between his mental and emotional life were typical of him and are illustrated by the fact that as a world leader in one branch of the armament industry he founded a prize for the champions of peace.

Alfred Nobel died in 1896. His will was very simple. The capital of his estate was to form a fund, the interest of which was to be distributed annually in the form of five prizes : one part each to the persons who shall have made the most important discovery or invention in the fields of physics and chemistry, these two prizes being awarded by the Swedish Academy of Science; one part to the person who shall have made the most important discovery in the domain of physiology or medicine, this to be awarded by the Caroline Institute in Stockholm; one part to the person who shall have produced the most out. standing work of an idealist tendency in the field of literature, the prize to be awarded by the Academy in Stockholm - the Swedish Academy; and one part to the person who shall have done the most or the best work for fraternity among nations, for the abolition or reduction of standing armies and for the holding and promotion of peace congresses, this to be awarded by a committee of five persons elected by the Norwegian Storting. In awarding the prizes no consideration was to be given to the nationality of the candidate.

The will was simple: to implement it was not easy. There were at first difficulties with the family, smoothed over by the firm and generous support to the will given by Emmanuel Nobel, the eldest of a family of nephews and nieces living in Russia. Then there was a not unnatural hesitation on the part of the awarding bodies to take on the novel responsibilities placed upon them by the will. These were in all cases overcome, and it will now be generally accepted that the statutes of the Nobel Foundation represent a most satisfactory scheme for carrying out the founder's intentions.

One word may be added as to the possible genesis of the various prizes. A clause in the will that * Nobel : the Man and his Prizes. By H. Schück, R. Sohlman, A. Osterling, G. Liljestrand, A. Westgren, M. Siegbahn, A. Schou and holm: Sohlmans Förlag, 1950.) $30 \mathrm{kr}$. preference should be given to those who "shall have conferred the greatest benofit on mankind" is reminiscent of the terms of award of the Rumford Medal of the Royal Society. Nobel's interest in literature was very deop. $\mathrm{He}$ had been deeply impressed by Shelley, and his outlook was deeply religious. In his worship of a God of peace and universal love of men, he adopted that atheism of Shelley which was essentially so close to Platonism and to basic Christianity. His support of a children's hospital and an earlier proposal to found a medical research centre in Paris, partly for blood transfusion, show that his coupling of "physiology and medicine" was not accidental but that he was interested in discoveries of a purely scientific nature as well as in those having an immediate practical value; while his Peace Prize, though not aimed directly at disarmament, which, he recognized, must come slowly, was rather based on the idea that peace would come when all nations agreed to take up arms together against any nation which first violated peace and began a war.

Reading the accounts of the work of the prize committees in the natural sciences, we receivo in concentrated form the history of the principal developments of these sciences over the past fifty years, both new discoveries and achievements of a different kind. This is particularly true of the section on the Prize for Physiology and Medicine, where much more is told of the reasons underlying the particular awards and of the competing subjects that were rejected than is given in the sections on the Prizes for Physics and for Chemistry. Each prize committee has its own rules as to what bodies or individuals are allowed to nominate candidates, with reasons given, for an award. The task of narrowing down the list each year to the final award is in general a very heavy one. At least eight months in each year is spent in investigation, examination and discussion of the works of the candidates nominated. The high regard in which Nobel prizemen are held the world over is a measure of the success and impartiality with which the task has been carried out.

The Prize for Physiology and Medicine has been divided between two candidates, generally for work in closely related fields, more frequently than any of the other prizes. During the fifty years under review, as many as 872 names were submitted to the electors -on an average more than 17 new names in a year. The number nominated varied considerably from year to year, from 89 in 1937 to 23 in 1944. The phrase "the domain of physiology or medicine" has been interpreted to mean "all the theoretical as well as the practical medical sciences" such branches of physiology as fall outside the medical sphere have not been taken into account.

Awards for successes in the unremitting war against disease naturally figure largely in the list, from the first prize in 1901 to Behring for sorum therapy and its application to diphtheria. Malaria (Laveran and Ross), typhus (Nicolle), tuberculosis (Koch), and pernicious anæmia (Whipple, Minot and Murphy) come in as specific cases, while more general awards were made for immunology and for anaphylaxis; the special importance of the human blood groups in blood transfusion was recognized in the award to Landsteiner. In chemothorapy, prontosil, 
penicillin and DDT were represented, while Finsen's phototherapy for lupus also drew an award. Hormones and vitamins bring into view thyroid diseases (Kocher) and the discovery of insulin (Banting and Macleod), while genetics and the function of chromosomes in heredity (Morgan) with the nature of embryonic development form one more branch of the domain covered by the prize. Turning to the more purely physiological field, we find represented the nervous system and the sense organs, digestion, circulation of the blood, respiration and excretion, the chemical structure of the body and intermediary metabolism. In much of this work one realizes how closely physiology and chemistry are linked, and one looks, not in vain, for awards of the Nobel Prize in Chemistry for subjects closely akin to some of the awards in physiology. Biochemistry clearly represents a field of interest to two sets of electors to Nobel prizes.

But let us turn aside for a moment to consider the Nobel Prize in Literature. Here we find a very great reluctance on the part of the awarding body, the Swedish Academy, to accept the responsibility laid on it : it was only the argument by Wirsén that its refusal would deprive leading men of letters of the financial reward and exceptional recognition which Nobel had in mind, which finally persuaded the Academy to accept. As it was, it had to face a storm when for various reasons Tolstoy was not chosen as the first prizeman (as a matter of fact he had never been nominated). The difficulty that faced the committee in judging the relative importance of candidates can be well understood if we consider some of the pairs between whom the choice finally lay in a given year; the name of the prizeman is given first in each case: Theodor Mommsen and Herbert Spencer ; Eucken, Swinburne and Lagerlöf ; Benavente and Yeats; Yeats and Hardy; Spitteler and Brandes; Sinclair Lewis and Dreiser. Carducci was one of the very few prize-winners who was chosen unanimously: the average age of the prizewinners is sixty-two, Mommsen being the oldest at eighty-five and Kipling the youngest at forty-two. France has received the highest number of the literature awards.

To return to scientific subjects, we take next the Nobel Prize for Chemistry. The first six awards were made to the elder statesmen in the chemical world when the Prize was founded: Van't Hoff, the founder of stereochemistry and the author of the laws of osmotic pressure, received the first prize. He was followed by Emil Fischer for his investigation into the structure of the sugars, and another German organic chemist, von Baeyer, the 'Grand Old Man' of organic chemistry; Arrhenius was elected as a prizeman for his work on electrolytic dissociation, William Ramsay for the discovery of helium, neon, krypton and xenon, Moissan for the isolation of fluorine and the introduction of the electric furnace. After these early awards, the Prize was given for work earried out almost entirely in the present century, and the subjects have been grouped conveniently under eight heads.

Under radioactivity and atomic chemistry we find the names of Mme. Curie for the discovery and isolation of radium, Rutherford for his work on the disintegration of the elements and the chemistry of radioactive substances, Soddy for his study of the origin and nature of isotopes, Aston for the results obtained by his mass-spectrograph and his discovery of the whole-number rule, Urey for the discovery of heavy hydrogen, Hevesy for his work on tracerelements, Joliot and Mme. Joliot-Curie for their synthesis of new radioactive elements, and Hahn for his discovery of the fission of heavy nuclei. To complete this story we must look to the awards made for the Prize for Physics.

But first we must examine other heads under which awards were made in chernistry. 'The constitution of organic compounds and biochemistry obviously are subjects closely linked with some of the awards in physiology. The work of Wieland and Windaus on the constitution of the bile acids and sterols respectively, that of Haworth, Karrer and Kuhn on carotenoids, flavine and vitamins $A$ and $B_{2}$, and that of Butenandt on sex hormones are sufficient to mention in this connexion. Work on other organic compounds such as chlorophyll (Willstätter), the alkaloids (Robinson) led to awards, while work on organic processes, such as fermentation, and on fermentative enzymes, was also recognized. Nutrition chemistry appears in the case of Virtanen's fodder preservation mothod. Micro-analysis is represented by Pregl, colloidal and surface chemistry by Zsigmondy, Svedberg, Tiselius and Langmuir. Ostwald, Nernst and Giauque represent dynamic chemistry and thermochemistry and the behaviour of substances at low temperatures. Technical developments were recognized in the work of Haber on the synthetic production of ammonia from its elements, and in the hydrogenation of coal and the development of chemical high-pressure methods. We return to physical chemistry in the work of Debye on dipole moments and molecular structure and on the diffraction of X-rays and electrons in gases.

The first award of the Nobel Prize for Physics was to Röntgen for the discovery of X-rays. As with the other prizes, the awards in the first few years were mainly for work done in the previous century, and all but three of those nominated for the first award eventually became Nobel prizemen-the three exceptions being ruled out (1) by the nature of his researches (W. W. Campbell), (2) by the early date at which his work had been done (Kelvin) and (3) by his early death (Nordenskiöld). The close nature of the tie between the prizes for physics and chemistry is revealed in the third award, which Mme. Curiewho afterwards got a Nobel Prize for Chemistryshared with her husband and Henri Becquerel for the study of spontaneous radiation, while in the following year Rayleigh got the Prize for Physics for the discovery of argon (and most fitly in the same year Ramsay got the Prize for Chemistry, as we have seen, for helium, neon, krypton and xenon).

The various branches in which physics has shown most vitality and progress in the past century are more closely interlocked than those in chemistry and physiology, and this is somewhat reflected in the account of the awards in physics given in the book. A few main lines can be followed through, some with obvious gaps to be supplied from the chemistry awards. Lenard's work on cathode rays was followed by J. J. Thomson's discovery of the electron. C. T. R. Wilson's cloud chamber revealed its value in the subsequent awards to Hess for work on cosmic radiation, to Anderson's discovery of the positron and to Blackett for development of the method and applications to nuclear physics and cosmic radiation. The discovery was recognized of fresh elementary particles, of which the neutron (Chadwick) has proved of immense importance. The meson was predicted successfully by Yukawa. New artificial 
radioactive elements produced by neutron irradiation secured an award for Fermi, while a very powerful method for accelerating charged particles was developed by Lawrence in the cyclotron. The idea that held in certain circles at the end of the past century that physics had nearly reached a stage of completion was completely killed by the workers mentioned above.

Another' line of development was linked with electromagnetic theory; Lorentz and Zeeman received the second Nobel Prize for Physics for their investigations of the influence of magnetism on the phenomena of radiation, Stark for the splitting of lines in electric fields and Michelson for his precision optical work, showing that no motion of the earth relative to the ether could be detected.

A revolutionary approach to the laws of radiation was developed in Max Planck's quantum theory. Niels Bohr's quantized atomic model led the way to noost important theoretical developments, while more immediately practical results came from Einstein's discovery of the law of the photo-electric effect, Franck's and Gustav Hertz's work on collisions between electrons and atoms, Raman's on the scattering of light, and A. H. Compton's work on the scattering of $\mathrm{X}$-rays in matter, and the Compton effect.

A further development, also revolutionary in character, followed from the quantum theory of radiation, which had in a sense ended the longstanding battle between the particle and the wave. theory of light. Prince Louis de Broglie applied the idea to particles of matter, and developed a theory that every particle is associated with a wave-motion -he discovered the wave nature of electrons, which was confirmed observationally by Davisson and G. P. Thomson. This work of de Broglie's in the hands of Schrödinger and Dirac led to fruitful developments of atomic theory, and to important new theorems such as Heisenberg's uncertainty principle and Pauli's exclusion principle. Dirac's work was tied up by Stern and Rabi with the magnetic moment of the proton and of atomic nuclei.

Von Laue's work on the diffraction of Röntgen rays by crystals, that of the Braggs on the analysis of crystal structure by means of X-rays, Barkla's work on the characteristic Röntgen radiation of the elements and Siegbahn's development of X-ray spectroscopy open up another chapter of research in physics.

Further, one must not forget in all this range of subjects considered by the electors as worthy of recognition $O$. W. Richardson's work on thermionics, the technical development of wireless telegraphy for which Marconi and Braun received an award, and also the investigations into the physical properties of the higher layers of the atmosphere which made Appleton a Nobel prizeman in physics.

We turn now to a different type of question. The award of the Nobel Peace Prize. Nobel's money, though derived mainly through explosives, was only in small part derived from military munitions, and there is no reason to doubt his sincere love of peace. He did remark in a letter to Baroness von Suttner, to whose influence the framework of the peace prize award is partly due, that his improvements in the means of destruction were more likely to make an end of war than her peace congresses. It is even more true to-day of some of the results arising from the work of many to whom awards have been made in prizes for chemistry and physics.
The first awards were made to two veteran pioneer peace-workers, Dunant, the creator of the International Red Cross, and Passy, founder of the International Permanent League of Peace. Other founders of world movements who were given the Nobel Peace Prize include Cremer, founder of the Inter-Parliamentary Conference and of what became later the International Arbitration League; Moneta, founder of an Italian peace body and an opponent of irredentism ; Fried, founder of Die Deutsche Friedensgesellschaft; Bertha von Suttner, founder of the Austrian Peace Organization; Bajer and Arnoldson, who founded the Danish and Swedish Peace Leagues, respectively (Bajer was also largely instrumental in founding the Bureau International Permanent de la Paix at Berne, which was run afterwards by Ducommun and Gobat), Jane Addams, founder of the Women's Peace Party, and Emily Balch, of the Women's International League for Peace and Freedom.

Another support of peace lies in international law, and the Committee in this connexion has awarded the Prize to the Institut de Droit International and to some of the leaders who bore the brunt of its work-Renault, Beernaert and Asser-the last-named turning largely to private international law. La Fontaine, another international jurist, actively opposed aerial warfare, while d'Estournelles worked as a politician for the Entente Cordiale.

Mediation and arbitration brought into view two statesmen of the United States, Theodore Roosevelt and Elihı Root. The First World War brought an award in 1917 to the Comité International de la Croix Rouge and in 1919 to Woodrow Wilson as founder of the League of Nations ; work at and for the League of Nations was recognized in the cases of Léon Bourgeois, Branting and Lange, while Nansen's work for returning prisoners of war and refugees from Russia drew a well-deserved reward. His International Office for Refugees received a second prize just before the outbreak of the Second World War.

Politicians, for their share in easing international tension, form another group of prize-winners : Dawes of the Dawes Plan, Kellogg of the Kellogg Pact, and Nicholas Murray Butler of the Carnegie Endowment from the United States, Austen Chamberlain from Great Britain, Briand and Stresemann (who quite suitably divided the Prize), Buisson and Quidde, each pair representing France and Germany.

The churches are surprisingly little represented in the awards, Archbishop Söderblom and John Mott being the only individuals singled out, while the Society of Friends is the only religious body. No one could deny the propriety of the award in their case.

With the war clouds gathering again in the 30's, the Committee turned to people representing the work for collective security and resistance to aggression. Norman Angell, Arthur Henderson and Lord Cecil of the Peace Ballot represent this phase, also Saavedra Lamas for his work as mediator between Bolivia and Paraguay. The case of Ossietzky is left for later discussion. The Second World War brought a second award to the Comité International de la Croix Rouge, an award to the British and Americans' Friends Service Councils, a recognition of the important services of Cordell Hull in laying the foundations of the United Nations Organization, the hope for future world peace, and of Lord Boyd-Orr for his contribution to the peace of the worldincreased food production. 
At the end of 1936 the Peace Prize Committee awarded the Prize for 1935 to Carl von Ossietzky, the German pacifist. At the time he was in a German concentration camp, and it was clear that the award was a clear-cut demonstration against the Nazi régime. The Norwegian foreign minister and a former foreign minister and prime minister had resigned from the Prize Committee in advance to avoid political complications, and later the Norwegian Storting resolved that members of the Nobel Committee upon becoming members of the Government must withdraw from the Committee. Ossietzky died in prison in 1938 without receiving any aid from the award. Hitler was violently resentful and issued a decree forbidding German nationals in future to accept any Nobel Prize. But his ban could not prevent the Swedish committees from awarding prizes to Germans if they so wished, and actually the Chemistry Committee did award prizes to Kuhn and Butenandt and the Physiology Committee to Domagk. Domagk was arrested by the Gestapo and compelled to sign a letter declining the Prize; similar letters were sent by Kuhn and Butenandt.

The money thus refused by the recipients of the awards passed to the corresponding institutes set up under the statutes of the Nobel Foundation. These were established to assist in the scrutiny necessary for adjudication of the prizes and for the promotion of the purposes of the Foundation. They include the Nobel Library, whose collection of modern belles-lettres is now in a class by itself, at least in Europe; the Nobel Medical Institute, founded in co-operation with the Swedish Government, with departments of biochemistry, cytology and neurophysiology ; the Nobel Institute, with a department of experimental physics in which a number of foreign students are carrying out researches; a department of chemistry is to be added before long. To complete the picture given by the statutes it only remains to describe the Norwegian Nobel Institute: its task is to guide the Committee in the award of the Peace Prize; it is a peace centre following the development of international relations and the work for their peaceful adjustment. It is associated with scholarly activities and also popular educational work for peaceful intercourse, justice and fellowship between nations.

Lastly, a few words about the statistics of the awards. Germany has provided the highest number of prize-winners, with the United States and the British Isles close behind. The United States have the highest number in medicine and peace, France in literature, Germany in chemistry and Great Britain in physics. The only case where one country has a substantial lead is Germany in the field of chemistry. The fact that Germany was ruled out for some years after 1939 makes comparison for different groups of years difficult; but looking through the lists one cannot but see the growing importance of the United States in later years. It is clear that the centre of first-class scientific research has shifted from Europe to the United States. This may be in part due to the greater resources available there, in part to the number of distinguished men of science who have settled there, in many cases as refugees, in part also to the exhaustion of European countries by two world wars ; but the reason for the change lies principally in the Americans themselves. They have had the opportunities; but they have also found the men to make use of them. While the performance of Great Britain, as revealed by the Nobel awards, has kept at a steady high level, that of the main European countries has very sadly fallen away, while that of the United States has risen remarkably. The United States stand to-day in the world of science where Germany stood fifty years ago.

Finally, a word of tribute must be paid to those who have written this book. They have all been active in the work of the Nobel Foundation in one capacity or another. They would all probably have echoed the words of Ragnar Sohlman, by whose death in 1948 the last link with the founder was lost, "I feel it an unforgettable experience to have taken part in the organisation of the Nobel Foundation". This he had done from the very first. It has been a great task that the various electing bodies have carried out. Entering upon it in many cases with misgiving and reluctance, they have so discharged their duties that Scandinavian honesty and impartiality have become widely recognized, and a general knowledge of and respect for northern eivilization have spread over the whole world. Alfred Nobel's ideas and ideals have proudly and successfully come alive under the wise guidance of those to whom he entrusted his great scheme.

F. J. M. Stratton

\section{PHYSICS OF RUBBER-LIKE MATERIALS*}

\section{BY DR. L. R. G. TRELOAR}

British Rayon Research Association, and the Davy Faraday Research Laboratory, Royal Institution

\section{Basis of Rubber Elasticity}

$7 \mathrm{O}$ account for the large elastic deformability of rubber-like materials, it is necessary to find a molecular mechanism involving comparatively longrange forces. The elasticity of ordinary solids may be satisfactorily explained in terms of the electrical fields of force between atoms, but, since these fields fall off rapidly with distance, such a mechanism cannot be expected to apply if the displacements of the relative positions of atoms are large. An approach based on concepts other than that of static intermolecular force fields must therefore be envisaged if, as is the case with rubber, deformations of the order of 500 per cent or more are involved.

In the development of theories of rubber, therefore, it is not surprising that we find a number of references to a loosely coiled or open network structure, composed either of long-chain molecules or of molecular bundles or micelles. In one form of this theory ${ }^{1}$, the network was imagined to form a 'gel skeleton' of high-molecular material, which provided the essential elasticity of the rubber, the space between the meshes being filled out with a low-molecular component of a viscous nature. This theory derived some support from the well-known fact that rubber may be divided by suitable solvents into two fractions, a soluble or 'sol' fraction of between 50 and 90 per cent, and a residual insoluble or 'gel' fraction. Later researches, however, have shown that this distinction is less fundamental than was at first thought, and that 'sol' rubber, if separated with exclusion of oxygen, possesses all the essential elastic properties of total rubber.

* Synopsis of four lectures given at the Royal Institution on November $2,9,16$ and 23 . 